\title{
A Description and Evaluation of U.S. Climate Reference Network Standardized Soil Moisture Dataset
}

\author{
RONALD D. LEEPER AND JESSE E. BELL \\ Cooperative Institute for Climate and Satellites-North Carolina, North Carolina State University, and \\ NOAA/National Centers for Environmental Information, Asheville, North Carolina \\ Michael A. PALECKI \\ NOAA/National Centers for Environmental Information, Asheville, North Carolina
}

(Manuscript received 12 October 2018, in final form 5 March 2019)

\begin{abstract}
The interpretation of in situ or remotely sensed soil moisture data for drought monitoring is challenged by the sensitivity of these observations to local soil characteristics and seasonal precipitation patterns. These challenges can be overcome by standardizing soil moisture observations. Traditional approaches require a lengthy record (usually 30 years) that most soil monitoring networks lack. Sampling techniques that combine hourly measurements over a temporal window have been used in the literature to generate historical references (i.e., climatology) from shorter-term datasets. This sampling approach was validated on select U.S. Department of Agriculture Soil Climate Analysis Network (SCAN) stations using a Monte Carlo analysis, which revealed that shorter-term (5+ years) hourly climatologies were similar to longerterm $(10+$ year) hourly means. The sampling approach was then applied to soil moisture observations from the U.S. Climate Reference Network (USCRN). The sampling method was used to generate multiple measures of soil moisture (mean and median anomalies, standardized median anomaly by interquantile range, and volumetric) that were converted to percentiles using empirical cumulative distribution functions. Overall, time series of soil moisture percentile were very similar among the differing measures; however, there were times of year at individual stations when soil moisture percentiles could have substantial deviations. The use of soil moisture percentiles and counts of threshold exceedance provided more consistent measures of hydrological conditions than observed soil moisture. These results suggest that hourly soil moisture observations can be reasonably standardized and can provide consistent measures of hydrological conditions across spatial and temporal scales.
\end{abstract}

\section{Introduction}

Soil moisture is an important component of the hydrological cycle that describes the availability of water for vegetation and the capacity of the soil to retain/ absorb incoming precipitation. As a result, observed (in situ and remotely sensed) or modeled soil moisture data can be readily applied to a variety of applications (Ochsner et al. 2013): monitoring and/or forecasting droughts (Otkin et al. 2016; Mo and Lettenmaier 2015; Hayes et al. 2012; Bell et al. 2015) and floods (Wright et al. 2018; Brocca et al. 2014; Crow et al. 2011), agriculture (Otkin et al. 2015; Mishra and Cherkauer 2010), construction (Ejem et al. 2017; Thorpe and Karan 2008), natural resource management

Corresponding author: Ronald D. Leeper, ronnieleeper@ cicsnc.org
(Groffman et al. 2014; West et al. 2009), and human health (Coopersmith et al. 2017), among others. Despite the increasing availability of soil moisture observations over the past decade, the widespread adoption of soil moisture data has been limited by the challenges of interpreting absolute (i.e., volumetric) measurements, which have well-known sensitivities to soil characteristics (Manns et al. 2014), land cover, elevation/slope (Brocca et al. 2007), and seasonal precipitation patterns (Bell et al. 2010; Manns et al. 2014; Xia et al. 2015). As a result, absolute measures of soil moisture can vary greatly over short distances, making it difficult to compare observations across local and regional scales or distinguish between dry and wet conditions at a location over time (Palecki and Bell 2013; Coopersmith et al. 2016). These spatial and temporal interoperability issues extend to the scientific community as well (Dirmeyer 2011; Wu et al. 2002; 
Leeper et al. 2017) as scientists explore the role of soil moisture in regional climate variability (Guo and Dirmeyer 2013; Findell and Eltahir 1997; Schär et al. 1999; Soulé 1990) and its links to the severity and persistence of floods and droughts (Mo 2011; Hong and Kalnay 2000; Bonan and Stillwell-Soller 1998).

Standardizing absolute observations can provide a relative measure of soil moisture conditions that account for these locational and seasonal variations with a more consistent measure of soil moisture conditions. A common approach to standardizing datasets is an empirical method based on a climatology derived over a historical reference period (Arguez et al. 2012). Traditionally, a climatology is based on the arithmetic mean, but it is not uncommon to have a median-based climatology for shorter-term datasets or those with outliers. From the climatology, anomalies (observation-climatology) or standardized anomalies (i.e., anomaly divided by standard deviation (for mean climatology) or interquartile range (for median) can be evaluated. These measures can be used to develop an empirical cumulative distribution function (ECDF) over the historical period to give current observations a percentile rank between 0 (the driest measurement) and 1 (wettest measurement). Another approach might be to apply the ECDF directly on volumetric soil moisture observations. Regardless of the approach, an advantage of these empirical approaches is that the historical reference period accounts for seasonal and locational variations in the data. One drawback is the assumption that the historical reference period provides an adequate distribution of plausible soil moisture conditions, which may not always be the case. This is why most empirical techniques require 30 or more years of data, which is problematic since most soil moisture observing systems (in situ and remotely sensed) over the United States have fewer than 10 years of data (Schaefer et al. 2007; Bell et al. 2013).

Recently, studies in the literature have explored the use of shorter-term historical reference periods with less than 30 years of data. For instance, in the most recent 1981-2010 climate normals from the National Oceanic and Atmospheric Administration's (NOAA) National Centers for Environmental Information (NCEI) provided an hourly supplemental normal (i.e., climatology) based on 10 years of automated observations from U.S. airports (Applequist et al. 2012). This short-term climatology was generated using a sampling of hourly measurements over a 15-day window (7 days before and after at the same hour) for each year over the period or record (Applequist et al. 2012). Similarly Ford et al. (2016) used a 31-day sampling window on daily soil moisture observations to measure differences between ECDF percentiles based on datasets with differing record lengths (Ford et al. 2016). In their study, Ford et al. (2016) showed that a 5-yr historical period of daily soil moisture data could reasonably reproduce percentiles derived from a longer-term (15 year) historical period. These studies suggest that shorter-term datasets can be reasonably used in empirically based standardization routines with little impact on their performance provided the short-term period captures the full range in soil moisture conditions.

The purpose of this study is to explore the use of empirically based methods to standardize hourly soil moisture observations. The availability of an hourly standardized soil moisture dataset can be particularly useful for subdaily-scale applications (i.e., flood monitoring) and ease the synchronization of data temporally with the results of modeling and remote sensing validation studies. In addition, the hourly standardized metrics can be aggregated (i.e., averaged, counts of exceedance, etc.) over weekly to seasonal time scales for drought monitoring and other long-term applications in a way that provides additional information (i.e., trends) about the variability of soil moisture conditions.

In this study, we propose to expand upon Ford et al. (2016) daily analysis by comparing hourly climatologies produced from long-term $(10+y r)$ and short-term $(<10 \mathrm{yr})$ data records. The climatology will be based on the sampling methodology mentioned earlier (Applequist et al. 2012) applied the U.S. Department of Agriculture's (USDA) Soil Climate Analysis Network (SCAN). SCAN has a long-term soil moisture record (10-20 yr) that will allow for the short- and long-term comparisons as well as an evaluation of how representative recent short-term periods are to the longer-term distribution. In addition, a series of empirically based standardized soil moisture metrics will be evaluated at U.S. Climate Reference Network (USCRN) stations and compared during differing stages of drought conditions as described by the U.S. Drought Monitor. The USCRN has 7-9 yr of hourly soil moisture data from which to evaluate differing approaches to standardizing soil moisture observations from diverse areas of the United States. It was anticipated that standardized measures of soil moisture conditions will provide improved insight into the evolution of hydrological conditions (drought intensification and amelioration) beyond absolute observations.

\section{Data}

\section{a. U.S. Climate Reference Network}

USCRN is a low-density network of 137 climate monitoring stations in the United States that observe 
TABLE 1. Selected SCAN site station name, state, latitude and longitude, start year, number of monitoring years (ending in 2017), and monitoring depths passing manual quality control review.

\begin{tabular}{llccccc}
\hline \multicolumn{1}{c}{ Site } & State & Lat & Lon & Start year & Year count & Monitoring depths (cm) \\
\hline Nunn & CO & 40.87 & -104.73 & 2003 & 15 & 20 \\
EROS Data Center & SD & 43.74 & -96.61 & 2003 & 15 & 5,10, and 20 \\
Fort Assiniboine & MT & 48.48 & -109.80 & 1997 & 21 & 5,10, and 20 \\
Table Mountain & MT & 45.80 & -111.59 & 2006 & 12 & 5,10, and 20 \\
Mandan & ND & 46.77 & -100.92 & 1997 & 21 & 10,20, and 50 \\
Adams Ranch & NM & 34.25 & -105.42 & 1997 & 21 & 5,10 , and 20 \\
Geneva & NY & 42.88 & -77.03 & 1997 & 21 & 5 and 10 \\
Crescent Lake & MN & 45.42 & -93.95 & 2003 & 15 & $5,10,20$, and 50 \\
Lind & WA & 47.00 & -118.57 & 1999 & 19 & 5 and 10 \\
Walnut Gulch & AZ & 31.73 & -110.05 & 2001 & 17 & 5 and 10 \\
Little River & GA & 31.5 & -83.55 & 2000 & 16 & 5,10, and 50 \\
Pee Dee & SC & 34.3 & -79.73 & 2002 & 16 & 5,10, and 20 \\
Youmans Farm & SC & 32.67 & -81.2 & 2002 & 16 & $5,10,20$, and 100 \\
Mount Mansfield & VT & 44.53 & -72.83 & 2002 & 5,10, and 20 \\
\hline
\end{tabular}

atmospheric (air temperature, precipitation, relative humidity, and $1.5-\mathrm{m}$ wind speed) and surface/subsurface (surface infrared temperature, soil moisture, soil temperature) climate variables (Diamond et al. 2013). The atmospheric sensors were deployed beginning in 2001 with soil sensors added to stations in the contiguous United States between 2009 and 2011 (Bell et al. 2013). The network monitors soil temperature and moisture conditions using the Hydra Probe II Soil Sensor Model SDI- $12^{1}$ of Stevens Water Monitoring Systems, Inc., which is a dielectric sensor operating at the $50-\mathrm{MHz}$ frequency. The dielectric observations are converted to volumetric soil moisture using the loam equation described in Seyfried et al. (2005). These sensors were installed in three sets at five depths $(5,10,20,50$, and $100 \mathrm{~cm}$ ) or two depths $(5$ and $10 \mathrm{~cm})$ depending on the site soil depth. The installation of three sets of probes surrounding the station mast aids in the preservation of data continuity (individual sensor outages) and assists data quality control efforts described by Bell et al. (2013). In this study, layer averages of available sensors at each depth were used to generate soil moisture climatologies and standardized metrics. Additional information about the USCRN network and soil monitoring efforts are provided in Diamond et al. (2013) and Bell et al. (2013), respectively.

\section{b. USDA Soil Climate Analysis Network}

SCAN is an irregularly distributed network consisting of over 200 stations across the United States that also observe above- and below-ground weather conditions. This network was used to evaluate the sampling method

\footnotetext{
${ }^{1}$ The USCRN Program does not endorse any specific commercial instrument models.
}

because it utilizes the same sensing technology installed at the same five depths as USCRN stations, but with a record of more than 11 years at some locations. A subset of SCAN stations were selected based upon data record length $(>11 \mathrm{yr})$, spatial distribution through several climate regions, and a manual review of data quality and homogeneity. A manual data quality check was applied to ensure that there were no obvious nonclimatic shifts in the data records from changes in sensor model and/or individual sensor replacement. This analysis resulted in the selection of 14 SCAN stations with $11+$ years of data from at least one depth with no obvious inhomogeneity (Table 1).

\section{c. U.S. Drought Monitor}

The U.S. Drought Monitor (USDM) team provides expert evaluations of drought conditions across the United States. The USDM map is produced jointly by the National Drought Mitigation Center (NDMC) at the University of Nebraska, USDA, and NOAA. USDM maps are released weekly and show the spatial distribution of drought by severity status (Table 2). The weekly maps are based on geophysical observations (e.g., precipitation anomalies, drought indices, streamflow, vegetation state, and others) and drought impacts reported by trusted experts effective on Tuesday morning of every week (Svoboda et al. 2002; Hayes et al. 2012). Historical drought conditions from the USDM GIS Data Files Archive (https://droughtmonitor.unl.edu/ Data/GISData.aspx) between 2009 and 2017 were extracted for each USCRN station in the conterminous United States. Weekly averages of USCRN volumetric, anomaly, percentile, and threshold exceedance counts were evaluated in comparison with differing degrees of USDM drought status at national and local scales. 
TABLE 2. U.S. Drought Monitor drought severity classification (Hayes et al. 2012).

\begin{tabular}{llc}
\hline \hline Category & \multicolumn{1}{c}{ Description } & Soil moisture percentiles \\
\hline None & Typical to wet & $>31$ \\
D0 & Abnormally dry & $21-31$ \\
D1 & Moderate drought & $11-20$ \\
D2 & Severe drought & $6-10$ \\
D3 & Extreme drought & $3-5$ \\
D4 & Exceptional drought & $0-2$ \\
\hline
\end{tabular}

\section{Method}

\section{a. Sampling method}

In this study, a sampling method was used to establish a station's historical reference period for each calendar hour based on the sampling period. The sampling period was defined as a set of days (sampling length) centered on a date and hour of interest that repeats annually over the period of record. Thus a historical period consists of a collection of hourly soil moisture observations over the sample period for the same hour, which accounts for any diurnal temperature dependencies in the dielectric soil moisture measurements as noted by Seyfried and Grant (2007). The sampling method increases the number of observations within the historical reference period by a factor of the sampling length. Historical periods that had more than $60 \%$ of the soil moisture observations missing were excluded in this study. This situation most commonly occurred for northern stations when soils were frozen. Frozen soil conditions are detected based on soil temperatures and removed by quality control checks because the dielectric probes used at in situ networks cannot detect ice. Alternate sampling approaches (not described here) were evaluated that included additional hours on either side of the current hour, but these were found to have minor impact on station standardization routines.

\section{b. Standardization methods}

Standardized hourly $5-\mathrm{cm}$ soil moisture observations from the USCRN were compared by generating time series of soil moisture percentiles using an ECDF. The ECDF in our method ranks from driest to wettest the soil moisture measures over the same historical period, and assigns a percentile to the target year/day/hour based upon the percentage of the observations that are equal to or less than that case. In this way, the percentile provides a measure of how common or rare a measure is for the date and hour.

The simplest approach considered in this study was based directly on volumetric soil moisture observations. In this method, raw volumetric observations over the historical period were used to generate separate ECDFs for each calendar hour. Volumetric observations were then converted to soil moisture percentiles using the appropriate ECDF for the respective calendar hour. The more sophisticated approaches constructed ECDFs based on soil moisture anomalies, which require the computation of a climatology over the historical reference period. In this study, anomalous soil moisture conditions were generated using climatologies derived from both the arithmetic mean and median. One additional approach considered divided station median anomalies by the interquartile range (the spread between the 25 th and 75 th soil moisture observation over the historical reference period) to create a standardized median anomaly. Standardized mean anomalies (division by standard deviation) were not considered because neither soil moisture observations nor anomalous conditions were normally distributed, which is an underlying assumption for this approach.

In the study, the four measures (raw volumetric, anomaly from the mean, anomaly from the median, and standardized anomaly from the median) as noted above were used to generate soil moisture percentiles using the same hourly historical reference period. These percentile time series will be referred to as the volumetric (VSM), mean anomaly (MNA), median anomaly (MDA), and standardized median anomaly (STA). The four percentile time series will be used to evaluate counts of hourly exceedances below the 2 nd $(<0.02), 5$ th $(<0.05)$, 10th $(<0.10)$, 20th $(<0.20)$, and 30th $(<0.30)$ percentiles. The choice of these thresholds corresponds to USDM drought classifications (i.e., D4-D0) described in Table 2.

\section{c. Sample and period of record length sensitivity study}

To evaluate the use of hourly soil moisture data in empirical standardization routines, data from SCAN stations were used to compute mean-based hourly soil moisture climatologies (Applequist et al. 2012). For the sake of brevity, the other methods for creating a climatological base (median climatology or direct volumetric) used in this study were not considered here. The computation of a soil moisture climatology was believed to be sensitive to both the length of the historical period and choice of sampling length or the number of days surrounding the target day/hour. To evaluate these sensitivities on station $5-\mathrm{cm}$ soil moisture climatology, a Monte Carlo simulation (e.g., Ford et al. 2016) was completed using select SCAN stations (Table 1). The Monte Carlo runs consisted of 1000 randomly chosen nonsequential sets of 3,5, 7, 9, and 11 annual periods (January-December) from each SCAN station's period of record to represent differing historical period lengths. 
For each of the randomized sets (1000 draws), sampling lengths of 1, 3, 7, 15, 31, and 45 days (e.g., Applequist et al. 2012) centered on the target date were used to derive over 30000 climatologies per station. These climatologies were used 1) to evaluate the appropriate sampling length to generate stable climatologies for short-term hourly time series of soil moisture observations and 2) to determine how well hourly climatologies from the most recent 7-yr period (USCRN's period of record) compared to the Monte Carlo distribution of the 1000 randomized draws for the appropriate sampling length run.

\section{d. USDM comparison}

In this study, USCRN hourly soil moisture observations and standardized measures were evaluated by USDM status relevant to each station and time. The intent of this analysis was to evaluate the performance of standardized measurements from local to national perspectives by comparing how volumetric and standardized soil moisture metrics describe the state of the soil moisture condition during drought.

Given the broad definitions of drought that span times scales from meteorological (days) to hydrological (seasons), USCRN volumetric and standardized measures of soil moisture conditions were averaged (exceedance counts summed) over 7-day periods ending at the hour corresponding to the USDM analysis: Tuesday at 1200 UTC. The deeper layers were excluded from this investigation because not all stations within the network monitor these depths. National volumetric and standardized soil moisture conditions were grouped by USDM status to evaluate mean conditions by drought severity class (from "none" to D4). Local analysis included examples from two USCRN stations during the 2012 drought that experienced rapid drought onset and improvement at Whitman, Nebraska, and Stillwater, Oklahoma, respectively.

\section{Results}

\section{a. Sensitivity of standardization to record and sampling lengths}

Monte Carlo simulations revealed that measures of error for the short-duration (sampled) climatology were relativity small when compared with SCAN's longerterm climatology. Averages of mean absolute error (MAE) and root-mean-square error (RMSE) ranged between 0.009 and $0.026 \mathrm{~m}^{3} \mathrm{~m}^{-3}$ and between 0.010 and $0.034 \mathrm{~m}^{3} \mathrm{~m}^{-3}$, respectively. The magnitude of errors decreased with the addition of more years and longer sampling lengths (Fig. 1). The rate of error reductions due to more years diminished after 5 , which was similar

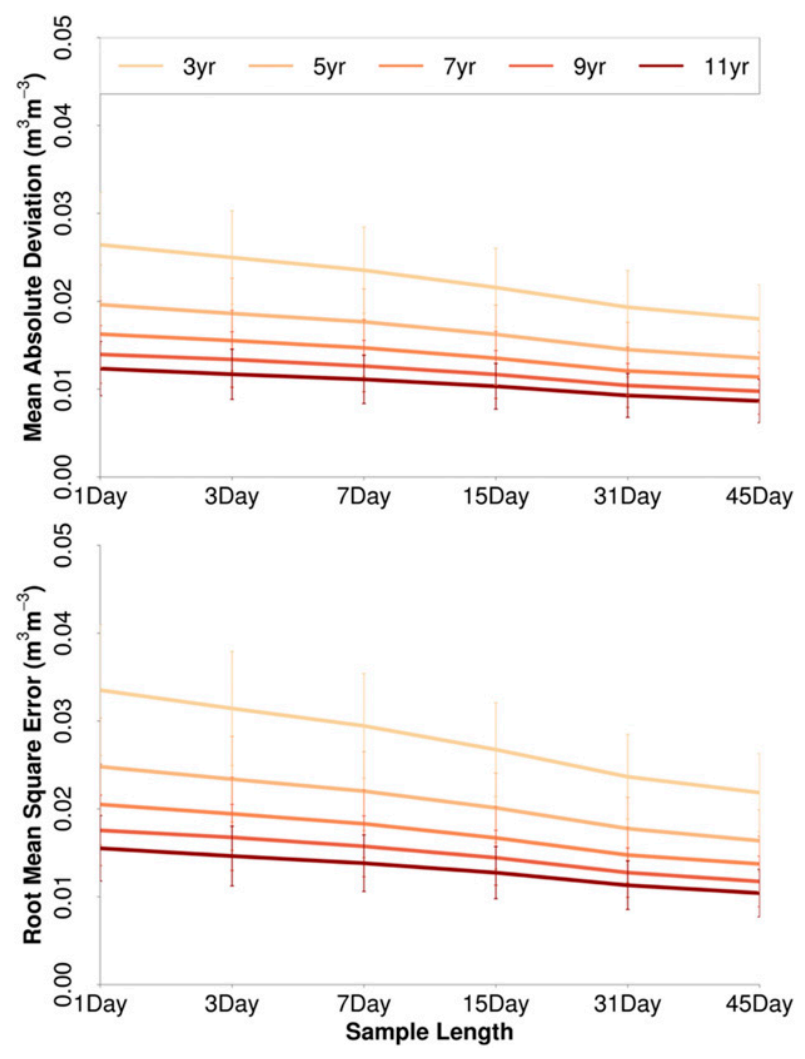

FIG. 1. The 1. 5-cm-depth (top) mean absolute deviation and (bottom) root-mean-square error for the 3-, 5-, 7-, 9-, and 11-yr Monte Carlo mean climatologies in comparison with the longerterm mean by sampling lengths $1,3,7,15,31$, and 45 days.

to Ford et al. (2016) results. Similarly, the magnitude of error declined very little between sampling lengths of 31 and 45 days. These results suggest that an hourly soil moisture climatology can reasonably represent a longerterm mean using the sampling approach with a 31-day sampling length on a dataset with 5 or more years of observations.

Analyses demonstrated that the most recent 7-yr period aligned well with the randomly drawn Monte Carlo distribution at most SCAN stations studied, but the standardized differences varied over the calendar year. Mean absolute deviation of the recent 7-yr hourly climatology was less than 0.34 standard deviations for all sample length windows tested of the 1000 randomly drawn 7-yr Monte Carlo climatologies (Fig. 2). The correspondence of the most recent 7-yr climatology with the long-term climatology varied by season (Fig. 3) and at some SCAN stations and times of year deviated from the Monte Carlo climatology by as much as 2 standard deviations. This is an important caveat of the approach, and suggests products based on a sampled climatology be well documented (i.e., base period clearly described) and updated regularly (i.e., annually). That said, the 


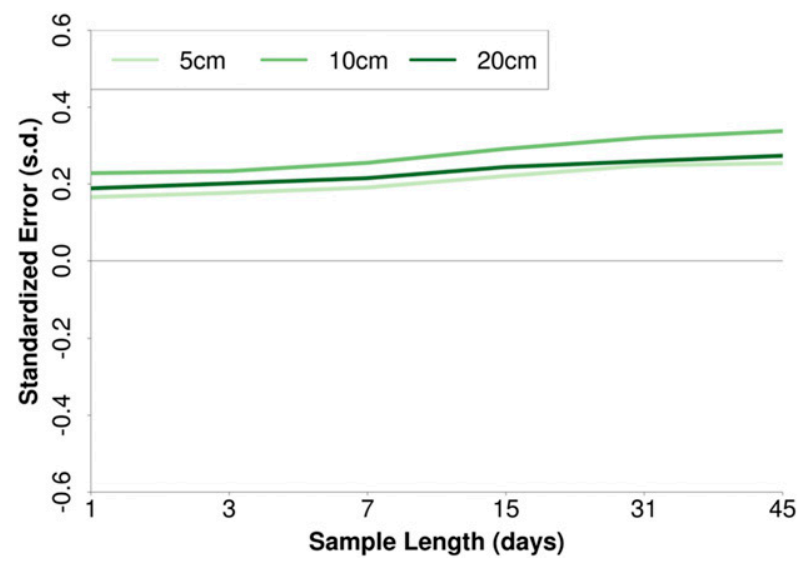

FIG. 2. The most recent 7-yr climatology mean absolute deviation from the 1000 randomized 7-yr Monte Carlo 5- (light green), 10(green), and 20-cm (dark green) climatologies.

small overall averaged errors indicate that the last seven years can produce reasonable estimates of longer-term $(10 \mathrm{yr})$ hourly soil moisture climatologies using the sampling method presented.

\section{b. USCRN soil moisture-USDM national comparison}

During the 2009-16 period of record for USCRN's soil moisture measurements, nationally averaged $5-\mathrm{cm}$ volumetric and standardized soil moisture metrics all decreased with increasing drought severity (Fig. 4). All metrics had their sharpest decline from nondrought to abnormally dry (D0) conditions. The metrics diminished more slowly with increasing drought intensity from D0 to D4. Mean and median anomalous soil moisture conditions displayed small changes resulting from the use of volumetric units in these anomalies as compared with the standardized median anomaly units. As would be expected, there were little to no average differences among the four empirical percentiles on a national level, as most ECDFs would stack the cases in the same or similar order, resulting in similar percentiles. This was also true for 7-day averages that underwent week-toweek worsening (D3 $\rightarrow$ D4) and improving (D3 $\rightarrow$ D2) USDM conditions (Fig. 4). While mean volumetric soil moisture conditions declined with higher drought categories, the decline is misleading. Since stations in desert climates like the U.S. Southwest have a much smaller and lower range of absolute volumetric soil moisture, this change is largely dominated by droughts occurring in places that normally have higher soil moisture levels. In sandy dry areas of the country, for instance, it is not uncommon to have mean soil moisture conditions below $0.1 \mathrm{~m}^{3} \mathrm{~m}^{-3}$, which according to national averages (Fig. 4) represents extreme drought conditions.
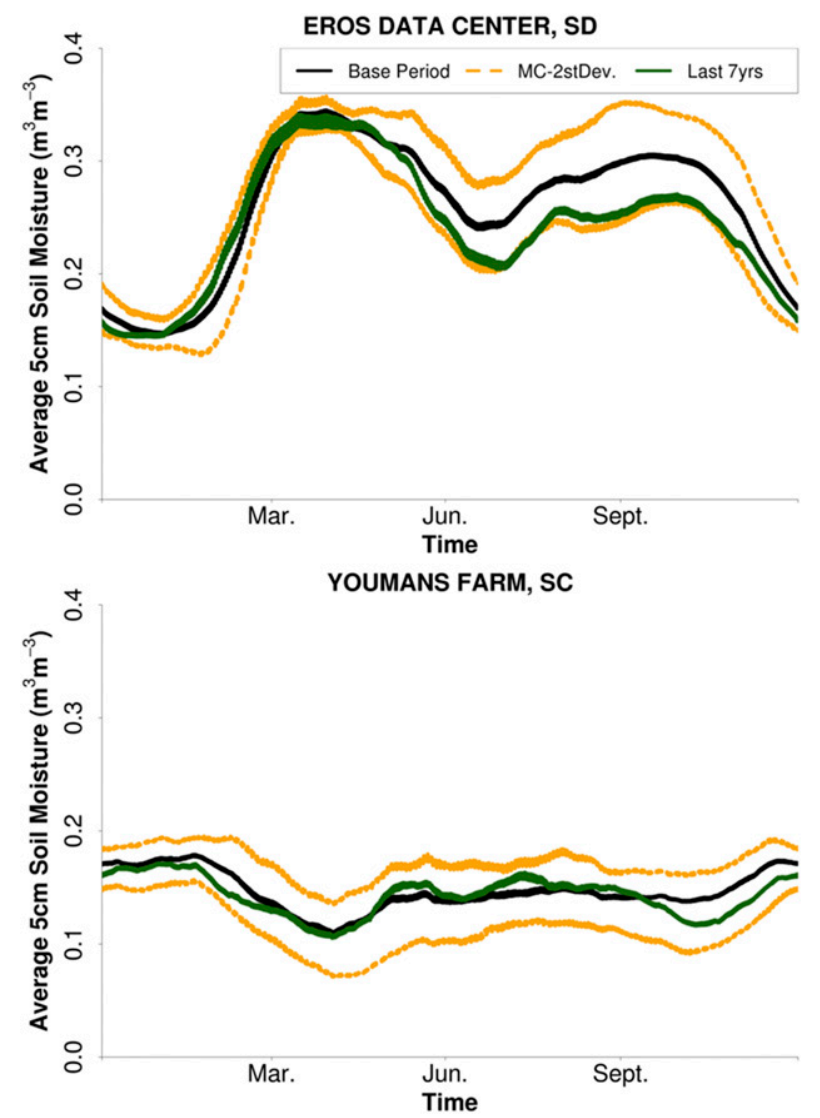

FIG. 3. Long-term (black curves) and last-7-yr (green curves) climatologies within 2 standard deviations of the 1000 randomized 7-yr draws of the Monte Carlo simulation (orange dashed curves) for the (top) Eros Data Center and (bottom) Youmans Farm.

To explore this further, the network was partitioned by dominate soil type (sandy vs silt/clay soils) based on laboratory analysis of soil samples taken when $5-\mathrm{cm}$ probes were installed, and by season. These results revealed that USDM category national averages of absolute volumetric soil moisture varied considerably more by dominate soil characteristic and season (Figs. 5a,c) than the anomaly soil moisture percentiles (Fig. 4). The relatively more stable soil moisture percentiles by soil characteristics reveals the value of a station-specific standardization (Figs. 5b,d), which extends to the other standardization methods given their level of agreement. An additional standardized measure that related even more strongly to drought severity was the count of threshold exceedance (Fig. 6). The percent of hours over the 7-day period that were less than the 20th percentile increased for all standardized measures from none to D4 conditions. This was particularly true for weeks having worsening USDM conditions. Overall, these results suggest that the nuances between the standardization approaches are negligible when 

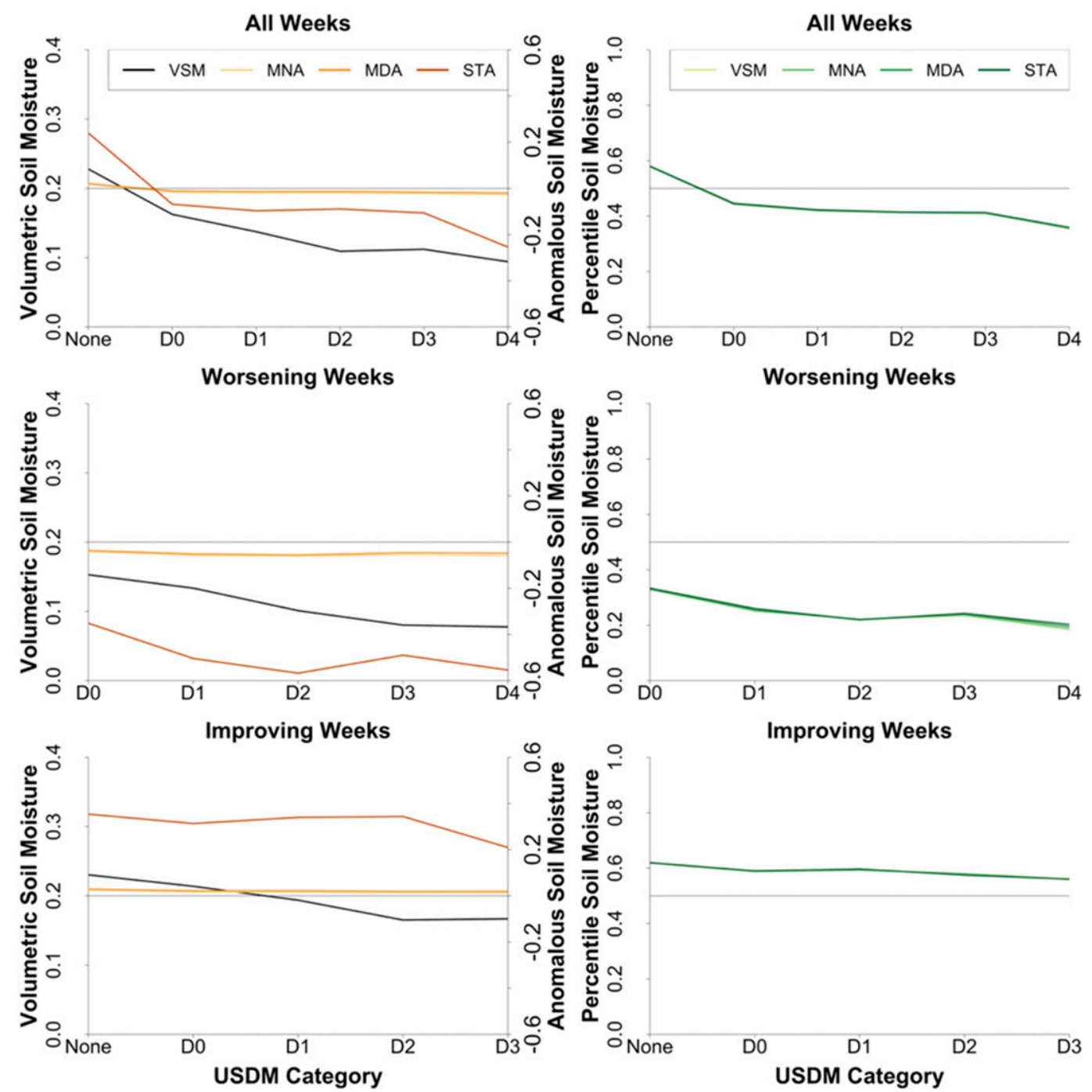

FIG. 4. (left) Nationally averaged 7-day means for U.S. Drought Monitor drought status levels: 5-cm absolute volumetric soil moisture (VSM; black), mean anomaly (MNA; yellow), median anomaly (MDA; orange) and standardized median anomaly (STA; red). Note that the MNA and MDA lines only slightly deviate from zero. (right) Nationally averaged percentile values for the four metrics (VSM, MNA, MDA, and STA) and USDM status levels display little difference between metrics. Shown are results for (top) all, (middle) worsening, and (bottom) improving weeks.

aggregating over national scales; however, local effects should not be discounted.

\section{c. Local case studies}

Throughout the 2012 growing season at Whitman the USDM reported the rapid onset of drought conditions with status changing from none to D2 in 4 weeks (Fig. 7) and to D4 within 13 weeks. Seven-day-averaged volumetric soil moisture conditions decreased slightly from 0.09 (the climatological average for this sandy location and time of year) to $0.04 \mathrm{~m}^{3} \mathrm{~m}^{-3}$ in mid- to late May, 2 weeks prior to the USDM placing the station in D0 drought. Volumetric conditions dried further to less than $0.01 \mathrm{~m}^{3} \mathrm{~m}^{-3}$ by early August. During this same period, 7-day-averaged anomalous conditions oscillated around near-normal $(\sim 0)$ conditions before dropping to $-0.04 \mathrm{~m}^{3} \mathrm{~m}^{-3},-0.04 \mathrm{~m}^{3} \mathrm{~m}^{-3}$, and -1.5 standard units for the mean, median, and standardized median anomalies, respectively. Interestingly, the standardized median anomalies rebounded somewhat following the 15 May drop, hovering around -0.7 standard units throughout the rest of the study period. Mean percentiles had a similar temporal response with percentiles for all metrics dropping from slightly above-normal conditions $(\sim 55 \%)$ to roughly $10 \%$ by mid-May. Differences among the various standardized percentiles were generally larger during the 

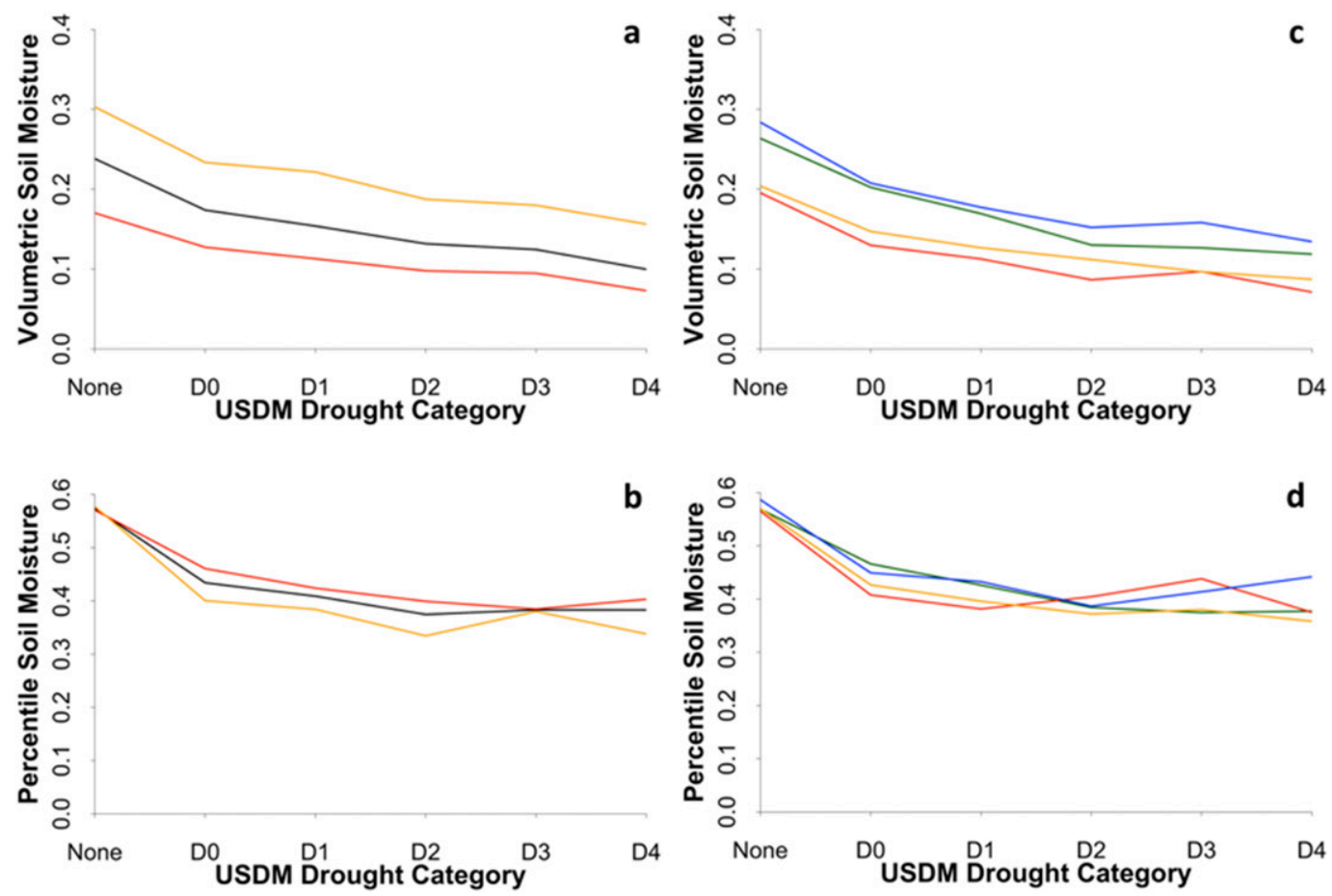

FIG. 5. National averages of USCRN (top) absolute volumetric and (bottom) percentile soil moisture conditions by USDM drought status and (a),(b) soil type and (c),(d) season. Dominant sand (red) and silt/clay (orange) station results were based on the 100 monitoring stations for which soil analysis were available: 57 sandy sites and 43 silt/ clay sites. The seasonal analyses were broken down by: December-February (winter; blue), March-May (spring; green), June-August (summer; red), and September-November (autumn; orange). Note that fewer stations are available in winter because of frozen ground.

summer season (from 15 May through 25 September). Overall, the percentile measures show just how significant a $0.05 \mathrm{~m}^{3} \mathrm{~m}^{-3}$ volumetric soil moisture drop was for this station and time of year. Similar to national averages, after the initial soil moisture percentile dropped, it hovered within the range between the 0th and 20th percentile for the remainder of 2012. Without some background knowledge of central Nebraska's sandy soils, the importance of the small $0.05 \mathrm{~m}^{3} \mathrm{~m}^{-3}$ drop in volumetric soil moisture could have been over looked by decision makers unfamiliar with local conditions. For this reason, the standardized soil moisture metrics provided information that is more comparable over time and geography concerning the severity of drought conditions than volumetric soil moisture alone.

The lingering drought from 2012 began to abate during the spring and summer months of 2013 at Stillwater (Fig. 7). Absolute volumetric soil moisture conditions over this same period slowly declined even as the USDM lowered its drought status from D3 to none. The reduction in volumetric soil moisture followed the normal seasonal pattern (Fig. 7, black line) related to an actively transpiring grassland and reduced precipitation. The reduction in volumetric soil moisture was contrary to improving hydrological conditions at this station visible in both anomalous and percentile conditions (Fig. 7). Measures of anomalous soil moisture conditions steadily increased from $-0.1 \mathrm{~m}^{3} \mathrm{~m}^{-3},-0.1 \mathrm{~m}^{3} \mathrm{~m}^{-3}$, and -1.0 standard units in March to $+0.14 \mathrm{~m}^{3} \mathrm{~m}^{-3}$, $+0.17 \mathrm{~m}^{3} \mathrm{~m}^{-3}$, and +1.4 standard units in late August for the 7-day-averaged mean, median, and standardized median anomalies, respectively. Similarly, all percentile measures increased throughout 2013 with notable rise from $10 \%$ to $80 \%$ over the 3 -week period ending 9 April 2013. Since the 7-day-averaged volumetric soil moisture conditions slightly decreased over the spring and summer months at Stillwater, it was clear that the standardized soil moisture metrics (anomalous and percentile conditions) provided a better description of the changes in the local hydrological state than absolute volumetric conditions alone.

\section{Discussion and conclusions}

In this study, we proposed standardizing hourly soil moisture observations from networks with shorter-term records using a sampling methodology. Monte Carlo simulations revealed little difference between sampled datasets with five or more years of soil moisture data. 

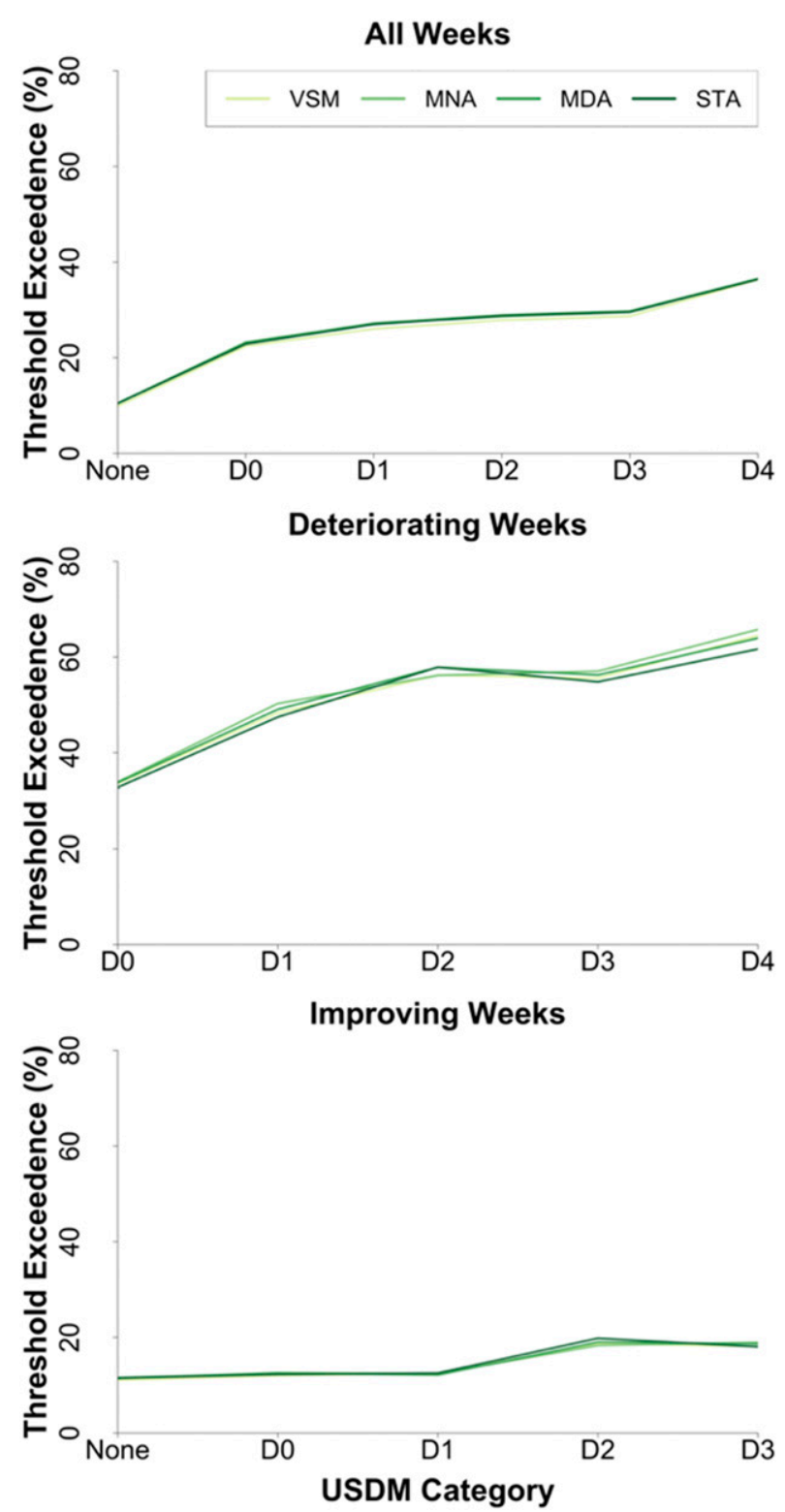

FIG. 6. National averages of the 5-cm 7-day percentage of hours below the VSM, MNA, MDA, and STA 20th percentiles by USDM drought classifications for (top) all, (middle) worsening, and (bottom) improving weeks.

However, these results were contingent on how representative the sampled soil moisture observations were to the possible range of soil moisture conditions. This could be an issue for a station that has seen similar hydrological conditions (either dry or wet) over much of its short period of record. In our study, nearly all of the select SCAN stations' recent sampled means were within 2 standard deviations of the 1000 randomly drawn 7-yr sampled means. These results indicate good agreement between randomly sampled and recently (last 7 years) sampled climatologies and that the sampling approach can be applied to hourly soil moisture observations from short-lived soil monitoring networks.

The sampling approach was used to compute several hourly standardized soil moisture measures (anomalies and percentiles), which were compared with unstandardized soil moisture observations. In this analysis, the utility of standardized soil moisture as opposed to absolute observed soil moisture conditions was particularly clear in the USDM analysis. For instance, standardized soil moisture conditions were found to be less sensitive to soil characteristics. In addition, national weekly counts of hours below critical soil moisture percentiles (i.e., $<20$ th percentile), which steadily increased with UDSM status, could serve as an indicator of hydrological trends (drought intensification versus amelioration). At the station level, weekly averages of soil moisture percentiles provided a more straightforward depiction of evolving hydrological conditions. In the two case studies explored here, the use of either standardized anomalies or soil moisture percentiles provided information on about hydrological conditions at stations without any of the background knowledge of a station's climate or soil profile.

However, there were some important differences between USCRN standardized soil moisture and a stations' USDM drought status. In the literature, soil moisture conditions are thought to describe meteorological to agricultural forms of drought, whereas the USDM's is a multiscale measure of drought, designed to capture drought from meteorological to hydrological perspectives. As a result, there were times when surface soil layers may moisten to high percentiles, indicating drought improvement at meteorological to agricultural scales, because of heavy rains despite moderate drought conditions from the USDM that were reflective of longerterm drought conditions (i.e., hydrological to ecological drought). This was likely due to differences of the temporal scales of the two measures. For instance, there are meteorological differences between a location in D3 status when the prior week was D2 versus D4. In the latter case, D3 status indicates drought improvement over last week, which from a meteorological and soil moisture condition perspective might indicate wet conditions. This explains why mean soil moisture percentiles by USDM status were remarkably different between drought worsening and improving weeks. In addition, meteorological and agricultural forms of drought tend to be leading indicators of drought initiation. This combined with the physical limit of soil moisture (wilting point) may help to explain why the top layer's mean soil moisture percentiles did not further degrade (lower) past D0 status at the national level. Additional analyses with a greater focus on individual drought events over different parts of the 

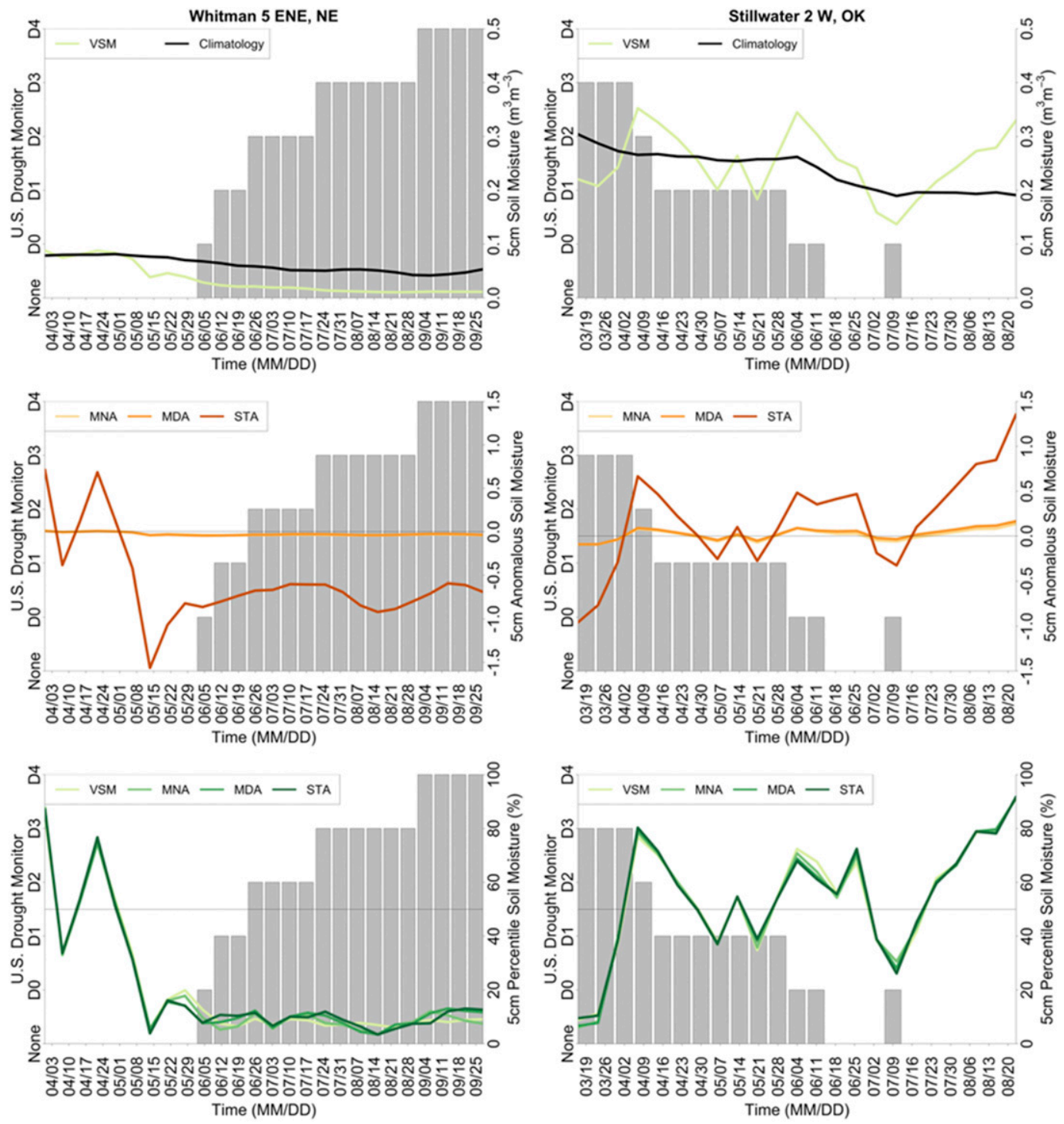

FIG. 7. The 7. 5-cm 7-day-averaged (top) VSM, (middle) MNA, MDA, and STA anomalies, and (bottom) VSM, MNA, MDA, and STA percentiles for soil moisture conditions at (left) Whitman during the rapid onset of drought conditions (gray bars) during the 2012 drought and (right) Stillwater during drought improvement in 2013. Standardized median anomalies were normalized by a factor of 10 in the middle panels to allow comparison with mean- and median-based anomalies.

country are currently under way. These analyses will include deeper soil layers where available, as these are necessary to fully evaluate the utility of standardized soil moisture measures.

Differences among the various methods used to process soil moisture information (anomalies, standardized anomalies, or straight volumetric soil moisture) were subtle. This was particularly true when the standardized measures were analyzed from a nationally averaged percentile perspective. At the station scale, there were discernible differences among the standardized percentiles, which ranged between $2 \%$ and $10 \%$ among most stations (not shown here) similar to Durham, North Carolina
(Fig. 8). However, there were stations with much larger differences. At Elgin, Arizona, differences between the mean-anomalous and other percentile peak over $+20 \%$ in some cases, which seemed to follow the of timing of the summer monsoon and winter precipitation seasons. This suggests that differences between standardization approaches may be related to subtle nuances in how the approaches describe the drier end of soil moisture spectrum. The lack of disparity of percentiles among the standardization methods suggest there is no clear advantage of using one method over another if the focus is on generating ECDF percentile time series. However, there may be applications where soil moisture anomalies, 

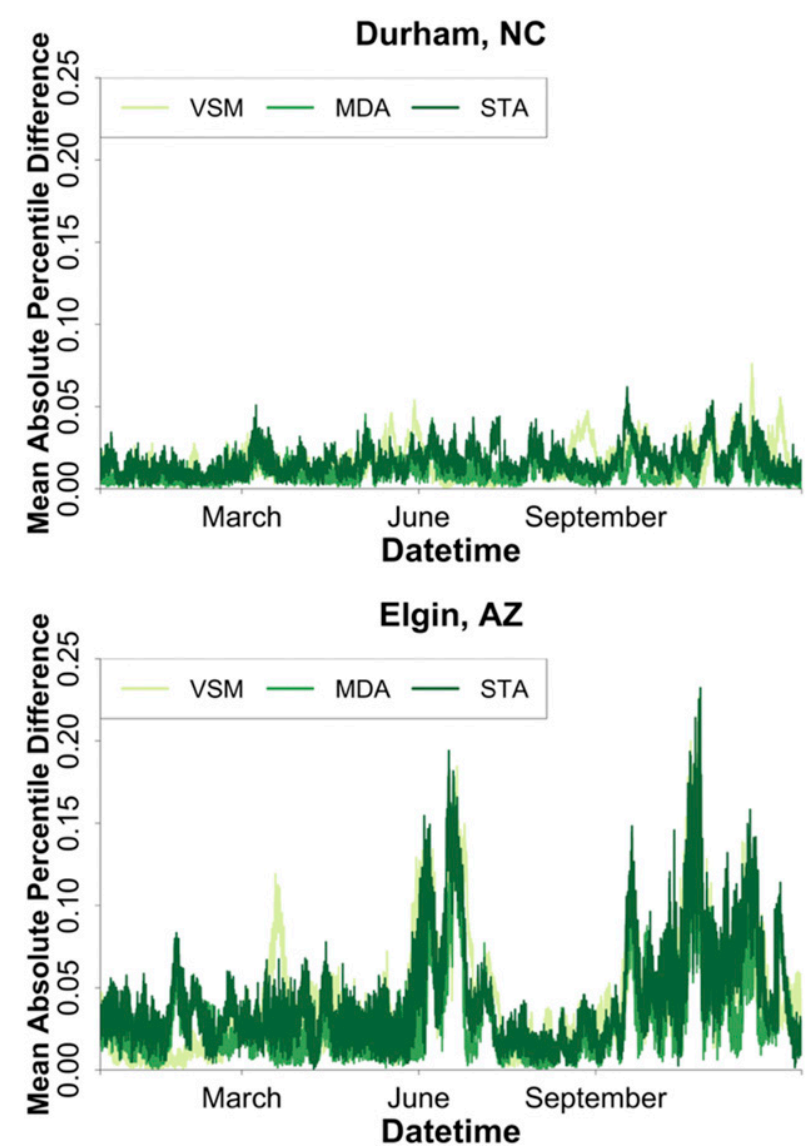

FIG. 8. The 5-cm calendar hourly sampled period mean absolute deviations between standardized mean and VSM, MDA, and STA percentiles for (top) Durham and (bottom) Elgin, which show the seasonal variations in standardized percentile differences.

particularly standardized anomalies, may prove useful such as accumulated anomalies to monitor hydrological deficits/surplus.

The soil moisture measures explored in this study (anomalies, standardized anomalies, percentiles, and counts of exceedance) provided substantial insight into hydrological conditions and trends during drought beyond absolute volumetric quantities. Furthermore, the availability of an hourly standardized soil moisture dataset provided additional information about intraweekly soil moisture variability that was better aligned with USDM status than 7-day averages. These intraperiod aggregates (i.e., counts of exceedance) based upon hourly data can be updated in near-real time, which is an important characteristic of drought indicators (Heim 2002), and perhaps serve as an indicator of drought trends (i.e., improving D3 vs worsening D3). While standardized percentiles may be beneficial in some applications, absolute volumetric quantities as well as anomalous conditions may be equally important in other cases, including numerical and satellite validation, soil moisture assimilation into weather and climate models, and irrigation calculations where soil moisture conditions are evaluated based on a physical baseline (i.e., wilting point, field capacity, etc.). As such, providing a comprehensive dataset that incorporates both standardized and nonstandardized measures of observed soil moisture conditions would be beneficial to a broader base of user communities.

Acknowledgments. This work was supported by NOAA through the Cooperative Institute for Climate and Satellites-North Carolina under Cooperative Agreement NA14NES432003. A special thanks is given to Scott Embler, Nancy Casey, and Michael Kruk for their contributions to this paper and to the anonymous reviewers who greatly improved it.

\section{REFERENCES}

Applequist, S., A. Arguez, I. Durre, M. F. Squires, R. S. Vose, and X. Yin, 2012: 1981-2010 U.S. hourly normals. Bull. Amer. Meteor. Soc., 93, 1637-1640, https://doi.org/10.1175/BAMS-D-11-00173.1. Arguez, A., I. Durre, S. Applequist, R. S. Vose, M. F. Squires, X. Yin, R. R. Heim Jr., and T. W. Owen, 2012: NOAA's 1981-2010 U.S. Climate Normals: An overview. Bull. Amer. Meteor. Soc., 93, 1687-1697, https://doi.org/10.1175/BAMS-D-11-00197.1.

Bell, J. E., R. Sherry, and Y. Luo, 2010: Changes in soil water dynamics due to variation in precipitation and temperature: An ecohydrological analysis in a tallgrass prairie. Water Resour. Res., 46, W03523, https://doi.org/10.1029/2009WR007908.

— moisture and temperature observations. J. Hydrometeor., 14, 977-988, https://doi.org/10.1175/JHM-D-12-0146.1.

—, R. D. Leeper, M. A. Palecki, E. Coopersmith, T. Wilson, R. Bilotta, and S. Embler, 2015: Evaluation of the 2012 drought with a newly established national soil monitoring network. Vadose Zone J., 14, vzj2015.02.0023, https://doi.org/10.2136/vzj2015.02.0023.

Bonan, G. B., and L. M. Stillwell-Soller, 1998: Soil water and the persistence of floods and droughts in the Mississippi River Basin. Water Resour. Res., 34, 2693-2701, https://doi.org/ 10.1029/98WR02073.

Brocca, L., R. Morbidelli, F. Melone, and T. Moramarco, 2007: Soil moisture spatial variability in experimental areas of central Italy. J. Hydrol., 333, 356-373, https://doi.org/ 10.1016/j.jhydrol.2006.09.004.

_ global rainfall from satellite soil moisture data. J. Geophys. Res., 119, 5128-5141, https://doi.org/10.1002/2014JD021489.

Coopersmith, E. J., M. H. Cosh, J. E. Bell, V. Kelly, M. Hall, M. A. Palecki, and M. Temimi, 2016: Deploying temporary networks for upscaling of sparse network stations. Int. J. Appl. Earth Obs. Geoinf., 52, 433-444, https://doi.org/10.1016/j.jag.2016.07.013.

—_, J. E. Bell, K. Benedict, J. Shriber, O. McCotter, and M. H. Cosh, 2017: Relating coccidioidomycosis (valley fever) incidence to soil moisture conditions. GeoHealth, 1, 51-63, https://doi.org/10.1002/2016GH000033.

Crow, W. T., M. J. van Den Berg, G. F. Huffman, and T. Pellarin, 2011: Correcting rainfall using satellite-based surface soil moisture retrievals: The Soil Moisture Analysis Rainfall Tool (SMART). Water Resour. Res., 47, W08521, https://doi.org/10.1029/2011WR010576. 
Diamond, H. J., and Coauthors, 2013: U.S. Climate Reference Network after one decade of operations. Bull. Amer. Meteor. Soc., 94, 485-498, https://doi.org/10.1175/BAMS-D-12-00170.1.

Dirmeyer, P. A., 2011: The terrestrial segment of soil moistureclimate coupling. Geophys. Res. Lett., 38, L16702, https:// doi.org/10.1029/2011GL048268.

Ejem, E. A., D. N. Dike, L. C. Njoku, U. Onwuka, C. C. Igboanusi, and U. N. Moneke, 2017: Analysis of factors of delay in road construction and other projects in Imo state. Int. J. Eng. Sci. Res. Tech., 6, 454-460.

Findell, K. L., and E. A. B. Eltahir, 1997: An analysis of the relationship between spring soil moisture and summer rainfall, based on direct observations from Illinois. Water Resour. Res., 33, 725-735, https://doi.org/10.1029/96WR03756.

Ford, T. W., Q. Wang, and S. M. Quiring, 2016: The observation record length necessary to generate robust soil moisture percentiles. J. Appl. Meteor. Climatol., 55, 2131-2149, https:// doi.org/10.1175/JAMC-D-16-0143.1.

Groffman, P. M., P. Kareiva, S. Carter, N. B. Grimm, J. Lawler, M. Mack, V. Matzek, and H. Tallis, 2014: Ecosystems, biodiversity, and ecosystem services. Climate Change Impacts in the United States: The Third National Climate Assessment, J. M. Melillo, T. C. Richmond, and G. W. Yohe, Eds., 195-219. U.S. Global Change Research Program, https://doi.org/10.7930/J0TD9V7H.

Guo, Z., and P. A. Dirmeyer, 2013: Interannual variability of landatmosphere coupling strength. J. Hydrometeor., 14, 16361646, https://doi.org/10.1175/JHM-D-12-0171.1.

Hayes, M. J., M. D. Svoboda, B. D. Wardlow, M. C. Anderson, and F. Kogan, 2012: Drought monitoring: Historical and current perspectives. Remote Sensing of Drought: Innovative Monitoring Approaches, B. D. Wardlow, M. C. Anderson, and J. P. Verdin, Eds., CRC Press/Taylor \& Francis, 1-19.

Heim, R. R., 2002: A review of 20th century drought indices used in the United States. Bull. Amer. Meteor. Soc., 83, 1149-1165, https://doi.org/10.1175/1520-0477-83.8.1149.

Hong, S., and E. Kalnay, 2000: Role of sea surface temperature and soil-moisture feedback in the 1998 Oklahoma, Texas drought. Nature, 408, 842-844, https://doi.org/10.1038/35048548.

Leeper, D. R., E. J. Bell, C. Vines, and M. Palecki, 2017: An evaluation of the North American Regional Reanalysis simulated soil moisture conditions during the 2011-13 drought period. J. Hydrometeor., 18, 515-527, https://doi.org/10.1175/JHM-D-16-0132.1.

Manns, H. R., A. A. Berg, P. R. Bullock, and H. McNarin, 2014: Impact of soil surface characteristics on soil water content variability in agricultural fields. Hydrol. Processes, 28, 43404351, https://doi.org/10.1002/hyp.10216.

Mishra, V. R., and K. Cherkauer, 2010: Retrospective droughts in the crop growing season: Implications to corn and soybean yield in the Midwestern United States. Agric. For. Meteor., 150, 1030 1045, https://doi.org/10.1016/j.agrformet.2010.04.002.

Mo, K. C., 2011: Drought onset and recovery over the United States. J. Geophys. Res., 116, D20106, https://doi.org/10.1029/ 2011JD016168.

- , and D. P. Lettenmaier, 2015: Heat wave flash droughts in decline. Geophys. Res. Lett., 42, 2823-2829, https://doi.org/ 10.1002/2015GL064018.

Ochsner, T. E., and Coauthors, 2013: State of the art in large-scale soil moisture monitoring. Soil. Sci. Soc. Amer. J., 77, 18881919, https://doi.org/10.2136/sssaj2013.03.0093.
Otkin, J. A., M. Shafer, M. Svoboda, B. Wardlow, M. C. Anderson, C. Hain, and J. Basara, 2015: Facilitating the use of drought early warning information through interactions with agricultural stakeholders. Bull. Amer. Meteor. Soc., 96, 1073-1077, https://doi.org/10.1175/BAMS-D-14-00219.1.

_ - and Coauthors, 2016: Assessing the evolution of soil moisture and vegetation conditions during the 2012 United States flash drought. Agric. For. Meteor., 218-219, 230-242, https:// doi.org/10.1016/j.agrformet.2015.12.065.

Palecki, M. A., and J. E. Bell, 2013: U.S. Climate Reference Network soil moisture observations with triple redundancy: Measurement variability. Vadose Zone J., 12, vzj2012.0158, https://doi.org/10.2136/vzj2012.0158.

Schaefer, G. L., M. H. Cosh, and T. J. Jackson, 2007: The USDA natural resources conservation service soil climate analysis network (SCAN). J. Atmos. Oceanic Technol., 24, 2073-2077, https://doi.org/10.1175/2007JTECHA930.1.

Schär, C., D. Luthi, and U. Beyerle, 1999: The soil-precipitation feedback: A process study with a regional climate model. J. Climate, 12, 722-741, https://doi.org/10.1175/1520-0442(1999) $012<0722$ :TSPFAP $>2.0 . \mathrm{CO} ; 2$.

Seyfried, M. S., and L. E. Grant, 2007: Temperature effects on soil dielectric properties measured at $50 \mathrm{MHz}$. Vadose Zone J., 6 , 759-765, https://doi.org/10.2136/vzj2006.0188.

, E. Du, and K. Humes, 2005: Dielectric loss and calibration of the Hydra Probe soil water sensor. Vadose Zone J., 4, 1070-1079, https://doi.org/10.2136/vzj2004.0148.

Soulé, T. P., 1990: Spatial patterns of multiple drought types in the contiguous United States: A seasonal comparison. Climate Res., 1, 13-21, https://doi.org/10.3354/cr001013.

Svoboda, M., and Coauthors, 2002: The Drought Monitor. Bull. Amer. Meteor. Soc., 83, 1181-1190, https://doi.org/10.1175/ 1520-0477-83.8.1181.

Thorpe, D., and E. P. Karan, 2008: Method for calculating schedule delay considering weather conditions. Proc. 24th Annual ARCOM Conf., Cardiff, United Kingdom, Association of Researchers in Construction Management, 809-818.

West, J. M., S. H. Julius, P. Kareiva, C. Enquist, J. J. Lawler, B. Petersen, A. E. Johnson, and M. R. Shaw, 2009: U.S. natural resources and climate change: Concepts and approaches for management adaptation. Environ. Manage., 44, 1001-1021, https://doi.org/10.1007/s00267-009-9345-1.

Wright, A. J., J. P. Walker, and V. R. N. Pauwels, 2018: Identification of hydrologic models, optimized parameters, and rainfall inputs consistent with in situ streamflow and rainfall and remotely sensed soil moisture. J. Hydrometeor., 19, 13051320, https://doi.org/10.1175/JHM-D-17-0240.1.

Wu, W., M. A. Geller, and R. E. Dickinson, 2002: The response of soil moisture to long-term variability of precipitation. J. Hydrometeor., 3, 604-613, https://doi.org/10.1175/15257541(2002)003<0604:TROSMT>2.0.CO;2.

Xia, Y., T. W. Ford, Y. Wu, S. M. Quiring, and M. B. Ek, 2015: Automated quality control of in situ soil moisture from the North American Soil Moisture Database using NLDAS-2 products. J. Appl. Meteor. Climatol., 54, 1267-1282, https:// doi.org/10.1175/JAMC-D-14-0275.1. 